\title{
Santiago Castroviejo Bolibar (1946-2009)
}

\author{
P. MONTSERRAT
}

Instituto Pirenaico de Ecología (CSIC), Jaca, España

El día treinta de septiembre de 2009 moría, tras larga enfermedad en Madrid, Santiago Castroviejo Bolibar, nacido el año 1946 en Moaña (Pontevedra). Era Profesor de Investigación del Consejo Superior de Investigaciones Científicas (CSIC) y académico de número de la Real Academia de Ciencias Exactas, Físicas y Naturales de España. Fue presidente durante unos años de la Real Sociedad Española de Ciencias Naturales, era Doctor en Biología por la Universidad Complutense y trabajaba en el Real Jardín Botánico de Madrid, del que fue Director durante muchos años.

Ha muerto con la ilusión -hasta el final- de continuar y terminar su obra, la Flora iberica que consideraba, y ciertamente lo es también de quienes él supo aglutinar en equipos jóvenes apropiados, junto con los ya veteranos en el estudio nuestra flora. Por mi edad avanzada (nací el 1918) soy de otra época, la de quienes trabajábamos con escasos medios y hemos llegado al florecimiento actual de la florística peninsular gracias a ese proyecto 'catalizado' por Santiago en el Jardín Botánico de Madrid. Él encauzó nuestra inquietud y perseveró en el empeño hasta el final de sus fuerzas.

Flora iberica centró su actividad como biólogo, botánico atraído por la vida de las plantas en su ambiente natural y con el deseo de conocerlas como indicadores ambientales que son. La flora española tenía problemas taxonómicos con especies desconocidas, algunas importantes por su biología, y urgía el conocerlas para orientar la gestión correcta de nuestros recursos vegetales. La flora más completa que teníamos el siglo pasado estaba en latín y mediado dicho siglo se inició la Flora Europaea, lo que pudo propiciar también el comienzo posterior de la nuestra, con la dedicación de Castroviejo al proyecto de su vida.
Recuerdo intentos anteriores y en especial la Primera Reunión de Botánica Peninsular al norte de Portugal: era el año 1948 y se habló de la flora pero nadie se atrevió a emprenderla. Proyectamos en Gerês los estudios monográficos sobre géneros difíciles, como fueron los realizados por Carlos Vicioso, Mariano Losa, Abilio Fernándes y su esposa, etc. Ya en la III Reunión celebrada en el Algarve

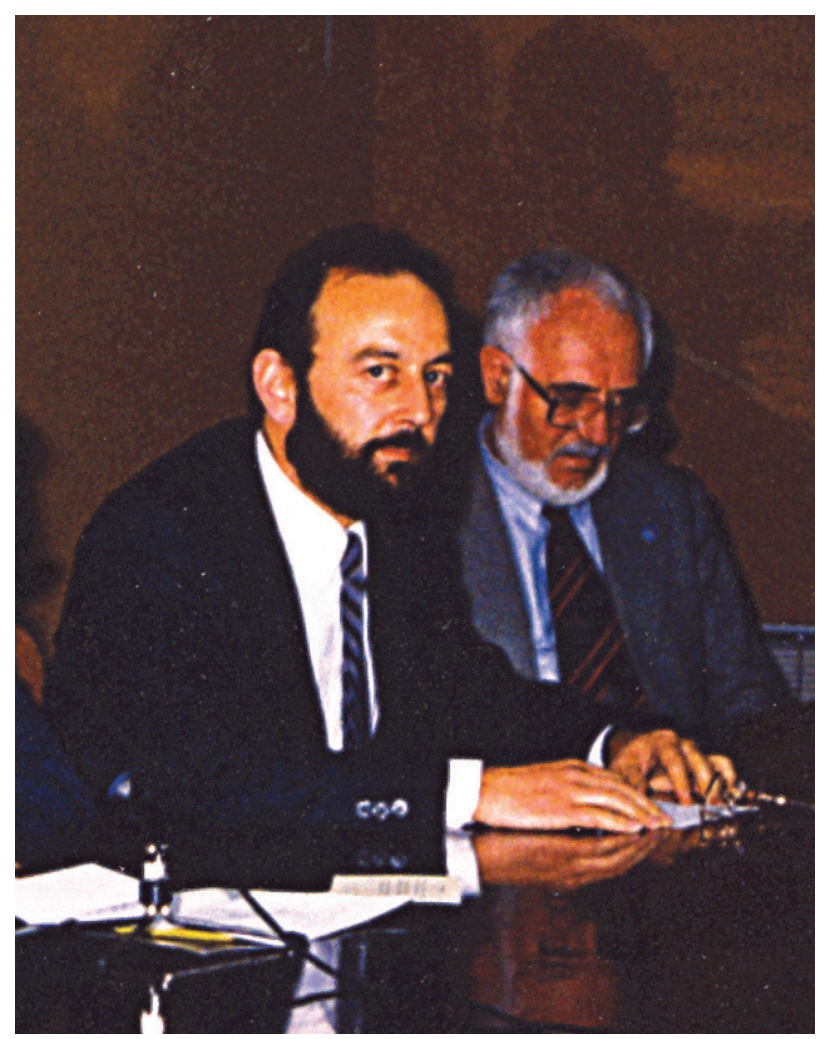

Santiago Castroviejo y Pere Montserrat en la presentación del tomo primero de Flora Iberica. 
portugués, 1968, discutimos mucho el nombre, la denominación del Proyecto, y se acabó sin concretar nada, por estar absorbidos los escasos taxónomos en sus colaboraciones para la citada Flora Europaea.

Castroviejo llegó en el momento preciso y supo aprovechar, encauzar la inquietud de todos, españoles y portugueses, para iniciar un proyecto viable que fue secundado y ha cambiado, renovado, diría más bien potenciado al veterano Real Jardín Botánico madrileño como centro de investigación biológica y botánica. Impulsó un cambio iniciado poco antes por el gran micólogo que fue su director Manuel Jordán de Urríes y el secretario Emilio Fernández Galiano.

Conocí y me examinó de Geobotánica en 1946 para el doctorado, el antiguo director Arturo Caballero y seguí frecuentando el Jardín Botánico después de su muerte, cuando Elena Paunero mantenía la relación internacional y Carlos Vicioso trabajaba por las tardes. Todo lo relacionado con nuestra flora fanerogámica estuvo muchos años como adormecido, en vida latente, hasta llegar al resurgir mencionado antes.

Como botánico e investigador profesional del CSIC que fui, puedo valorar la importancia de iniciar y mantener con seguridad un Proyecto de Investigación, en este caso internacional: es obvio que fue posible gracias a nuestra investigación nacional bien organizada y eficaz. Santiago encontró apoyo y puso su dedicación para desarrollarlo; destaco ahora esa seguridad institucional que pudo potenciar sus cualidades personales y mantenerlo todo con un desarrollo progresivo durante treinta años ininterrumpidos.

\section{La modernización del Jardín Botánico madrileño}

La elaboración de una flora crea necesidades que se han ido cubriendo: es como un organismo que crece y a ello ha contribuido, sin ninguna duda, el proyecto liderado por Santiago. El esfuerzo por reunir en el Jardín Botánico buenos materiales de herbario y adecuados recursos bibliográficos otorga una gran autonomía de trabajo y facilita el desarrollo de nuevas iniciativas. En consecuencia, el Jardín actuó de catalizador que permitió la expansión de la taxonomía y sistemática botánica en España.
Este amplio desarrollo que reconocen hoy todos nuestros colegas europeos, ha redundado a su vez en la continuación del proyecto de Flora iberica, proyecto al que han contribuido muchos botánicos penisulares. Ese resurgir del Botánico madrileño con seguridad aún tendrá mayor trascendencia que los 15 volúmenes de flora ya publicados. Todo es debido a su trabajo en equipo y a la colaboración eficaz con otros equipos regionales, además de los portugueses implicados en el Proyecto de Flora iberica, la ilusión continuada de Castroviejo

\section{Otras obras florísticas peninsulares}

En Coimbra de Portugal se conserva el herbario de Willkomm básico para nuestra flora y allí estuvimos con Santiago cuando aún vivían Abilio Fernándes y su esposa; el activo colaborador de Flora iberica Jorge Paiva continúa junto con los botánicos jóvenes portugueses, como la profesora Sales y otros. Castroviejo cuidó mucho esa participación esencial para su proyecto internacional.

La flora de Oriol de Bolòs y Josep Vigo es Flora Básica para Flora iberica y con Santiago comentamos su volumen tercero el año 1997, en Anales Jardín Botánico de Madrid, 55 (1): 234-240. Para mí fue una ocasión excelente para conocer su calidad humana, con orientación edificadora, positiva.

Los herbarios del Instituto Botánico de Barcelona BC y la Universidad BCN contribuyen también activamente secundando la idea del gran botánico Pius Font Quer de conocer bien la Flora del Mediterráneo occidental. Los trabajos de Flora iberica se completan con los del norte de África y la Medcheklist mediterránea, con las floras de Andalucía, etc. Me gustaría ser joven.

Santiago era organizador, estaba convencido de que un orden establecido atrae más orden y lo demostró desde que se iniciara el Proyecto en 1981. Le traté personalmente y en muchas ocasiones, tanto en la montaña como en el Botánico, donde pude apreciar su enorme humanidad, hasta cariño para quienes le trataban en y fuera del trabajo: contagiaba ilusión, un convencimiento de lo que se inicia bien puede seguir y finalizará. Y con esa base, estamos todos preparados para que se pueda completar Flora iberica: así, su conclusión será nuestro mejor homenaje, a él y a su memoria. 